\title{
Glutamine involvement in nitrogen regulation of cellulase production in fungi
}

\author{
Ai-Ping Pang ${ }^{1}$, Funing Zhang ${ }^{1}$, Xin $\mathrm{Hu}^{1}$, Yongsheng Luo ${ }^{1}$, Haiyan Wang ${ }^{1}$, Samran Durrani ${ }^{1}$, Fu-Gen Wu ${ }^{1}$, \\ Bing-Zhi Li ${ }^{2}$ Zhihua Zhou ${ }^{3}$, Zuhong Lü ${ }^{1 *}$ and Fengming Lin $^{1 *} \mathbb{D}$
}

\begin{abstract}
Background: Cellulase synthesized by fungi can environment-friendly and sustainably degrades cellulose to fermentable sugars for producing cellulosic biofuels, biobased medicine and fine chemicals. Great efforts have been made to study the regulation mechanism of cellulase biosynthesis in fungi with the focus on the carbon sources, while little attention has been paid to the impact and regulation mechanism of nitrogen sources on cellulase production.
\end{abstract}

Results: Glutamine displayed the strongest inhibition effect on cellulase biosynthesis in Trichoderma reesei, followed by yeast extract, urea, tryptone, ammonium sulfate and L-glutamate. Cellulase production, cell growth and sporulation in T. reesei RUT-C30 grown on cellulose were all inhibited with the addition of glutamine (a preferred nitrogen source) with no change for mycelium morphology. This inhibition effect was attributed to both L-glutamine itself and the nitrogen excess induced by its presence. In agreement with the reduced cellulase production, the mRNA levels of 44 genes related to the cellulase production were decreased severely in the presence of glutamine. The transcriptional levels of genes involved in other nitrogen transport, ribosomal biogenesis and glutamine biosynthesis were decreased notably by glutamine, while the expression of genes relevant to glutamate biosynthesis, amino acid catabolism, and glutamine catabolism were increased noticeably. Moreover, the transcriptional level of cellulose signaling related proteins ooc1 and ooc2, and the cellular receptor of rapamycin trFKBP12 was increased remarkably, whose deletion exacerbated the cellulase depression influence of glutamine.

Conclusion: Glutamine may well be the metabolite effector in nitrogen repression of cellulase synthesis, like the role of glucose plays in carbon catabolite repression. Glutamine under excess nitrogen condition repressed cellulase biosynthesis significantly as well as cell growth and sporulation in T. reesei RUT-C30. More importantly, the presence of glutamine notably impacted the transport and metabolism of nitrogen. Genes ooc1, ooc2, and trFKBP12 are associated with the cellulase repression impact of glutamine. These findings advance our understanding of nitrogen regulation of cellulase production in filamentous fungi, which would aid in the rational design of strains and fermentation strategies for cellulase production in industry.

Keywords: Glutamine, Cellulase, Nitrogen metabolism, The TOR pathway, ooc1, trFKBP12

*Correspondence: zhlu@seu.edu.cn; linfengming@seu.edu.cn 1 State Key Laboratory of Bioelectronics, School of Biological Science and Medical Engineering, Southeast University, Nanjing, China Full list of author information is available at the end of the article

\section{Background}

In nature, organisms sense nutrient availability in the surrounding environment and adjust their metabolism for optimal growth, development, and reproduction [1]. Carbon and nitrogen are two of major elements required for life. In fungi, nitrogen metabolism is controlled by a complex genetic regulatory circuit which ensures the original author(s) and the source, provide a link to the Creative Commons licence, and indicate if changes were made. The images or other third party material in this article are included in the article's Creative Commons licence, unless indicated otherwise in a credit line to the material. If material is not included in the article's Creative Commons licence and your intended use is not permitted by statutory regulation or exceeds the permitted use, you will need to obtain permission directly from the copyright holder. To view a copy of this licence, visit http://creativecommons.org/licenses/by/4.0/. The Creative Commons Public Domain Dedication waiver (http://creativeco mmons.org/publicdomain/zero/1.0/) applies to the data made available in this article, unless otherwise stated in a credit line to the data. 
preferential use of primary nitrogen sources (ammonium and glutamine) and also confers the ability to use many different secondary nitrogen sources (i.e., nitrate) when appropriate [2-6], which is similar to carbon catabolite repression (CCR). Most genes encoding nitrogen catabolic enzymes are subject to nitrogen catabolite repression (NCR), mediated by positive-acting transcription factors of the GATA family of proteins. The standard model of NCR is that AreA mediates de-repression of genes for utilization of secondary nitrogen sources in the absence of ammonium or glutamine. The quality and quantity of nitrogen impact the biosynthesis of many known secondary metabolites in fungi $[7,8]$, such as cellulase in Penicillium occitanis [9] or Penicillium funiculosum [10], gibberellin in Gibberella fujikuroi [11], deoxynivalenol in Fusarium graminearum [12], and aflatoxin in Aspergillus flavus [13]. Study has been making progress on the effect and regulation mechanism of nitrogen sources on cellulase production.

Nitrogen metabolism plays an important role in cellulase production in filamentous fungi like $T$. reesei, Aspergillus nidulans, and P. funiculosum. In T. reesei, deletion of the global nitrogen regulator Are1 decreased cellulase production when using $\left(\mathrm{NH}_{4}\right)_{2} \mathrm{SO}_{4}$ as the nitrogen source, demonstrating a role of Are1 in the regulation of cellulase production [14]. In A. nidulans, cellulase production is impacted by both carbon and nitrogen source, and is under the regulation of the carbon regulators $\mathrm{CreA}, \mathrm{CreB}$, and $\mathrm{CreC}$, as well as the nitrogen regulator AreA, either directly or indirectly [15]. Meanwhile, efforts have been put on optimizing nitrogen sources for cellulase production. A sequential experimental design methodology has been explored for nitrogen source optimization for the enhancement of cellulase production in $P$. funiculosum by evaluating various nitrogen sources including ammonium sulfate, urea, yeast extract, and peptone [10]. Suitable nitrogen sources for cellulase production have been described for $T$. reesei $[16,17]$. $T$. reesei can consume a variety of nitrogen-containing compounds with little change in cellulase production, while nitrogen limitation inhibited cell growth and cellulase biosynthesis [17]. However, compared to the extensive research on the carbon regulation on cellulase production [18-25], less attention has been paid to nitrogen regulation of cellulase production with the underlying mechanism unknown.

To investigate the nitrogen regulation of cellulase production in fungi, we evaluated the influence of various nitrogen sources on cellulase production under excess complex nitrogen condition, finding that glutamine exhibited the strongest inhibition effect on cellulase biosynthesis. Then the effect of glutamine on T. reesei RUTC30 grown under cellulase-producing condition was investigated in terms of cellulase synthesis, cell growth, sporulation ability, and morphology. The molecular mechanism behind glutamine-repressed cellulase production was explored by comparative transcriptional profiling and the knockout of genes ooc1, ooc2, and trFKBP12.

\section{Results}

Glutamine exhibited stronger inhibition effect on cellulase biosynthesis than other nitrogen sources under excess

\section{complex nitrogen sources}

First, we explored the impact of the addition of equal amount of varied nitrogen sources into Trichoderma minimal media (TMM) on cellulase production, including glutamine, glutamate, ammonium sulfate, yeast extract, tryptone, and urea (Fig. 1A). The addition of different nitrogen sources at $2.92 \mathrm{~g} / \mathrm{L}$ inhibited enzyme activities and protein secretion to varying degrees, of which glutamine had the most severe inhibition effect, followed by yeast extract, urea, tryptone, ammonium sulfate and glutamate. In the presence of glutamine, the FPase, CMCase, pNPCase, pNPGase and pNPXase activities and secreted protein at $72 \mathrm{~h}$ were decreased by $93.27 \%, 98.22 \%, 87.33 \%, 92.48 \%, 87.81 \%$, and $53.54 \%$, respectively, as compared to those of RUT-C30 cultured in only TMM. Clearly, the inhibition effect on cellulase biosynthesis was found for all the tested types of nitrogen sources, indicating that the addition of more nitrogen into TMM caused nitrogen excess that compromised the cellulase production (given that TMM already contains complex nitrogen sources including $4 \mathrm{~g} / \mathrm{L}$ ammonium sulfate, $1 \mathrm{~g} / \mathrm{L}$ urea, $0.75 \mathrm{~g} / \mathrm{L}$ tryptone, and $0.25 \mathrm{~g} / \mathrm{L}$ yeast extract). On the other hand, the huge difference on cellulase production repression between glutamate and glutamine suggested that the extent of cellulase inhibition is also dependent on the types of nitrogen sources. Meanwhile, this result demonstrated that cellulase production was much more sensitive to glutamine than other nitrogen sources under excess nitrogen conditions.

When using each tested nitrogen source of $4 \mathrm{~g} / \mathrm{L}$ as the sole nitrogen source to replace all the nitrogen sources in TMM, excellent cellulase activities were observed for most of the nitrogen sources, except urea (Fig. 1B). The highest (hemi)cellulase activities were found on glutamine, ammonium sulfate, or glutamate, followed by tryptone, yeast extract, and urea (Fig. 1B).

\section{High dose glutamine exerted a repression on (hemi) cellulase production in $T$. reesei}

In detail, the effect of glutamine on (hemi)cellulase production of T. reesei RUT-C30 under cellulase-producing condition was further investigated by adding different physiological levels of glutamine $(0,0.58,1.46$, 

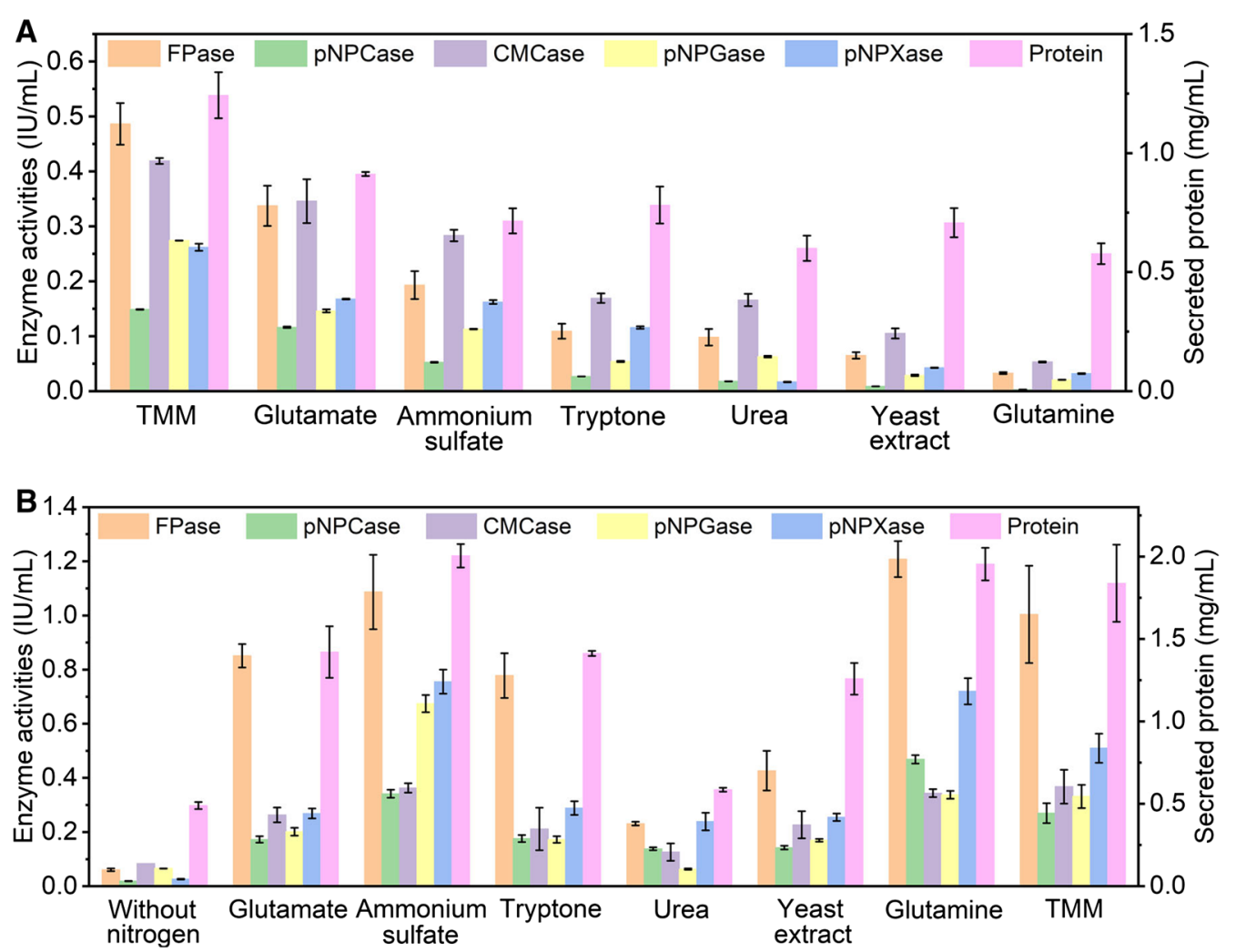

Fig. 1 Effect of different nitrogen sources on (hemi)cellulase activities and protein secretion of T. reesei RUT-C30 at 72 h. A Enzyme activities of T. reesei RUT-C30 cultured in TMM with the individual addition of different nitrogen sources of $2.92 \mathrm{~g} / \mathrm{L}$. B Enzyme activities of T. reesei RUT-C30 cultured with different nitrogen sources as a sole nitrogen source at $4 \mathrm{~g} / \mathrm{L}$. FPase: the filter paper activity; pNPCase: the CBH activity; CMCase: the CMC activity; pNPGase: the $\beta$-glucosidase activity; pNPXase: the $\beta$-xylosidase activity; Secreted protein: secreted protein concentration. Data are represented as the mean of three independent experiments and error bars express the standard deviations

and $2.92 \mathrm{~g} / \mathrm{L}$ ) into $\mathrm{TMM}+2 \%$ cellulose (Fig. 2A). As the concentration of glutamine was increased from 0.58 to $2.92 \mathrm{~g} / \mathrm{L}$, the increasing rate of (hemi)celluase activities and secreted protein concentration along the fermentation time were lowered continuously, showing that the (hemi)cellulase production was repressed by the treatment of glutamine. The addition of $2.92 \mathrm{~g} / \mathrm{L}$ glutamine severely blocked cellulase production, leading to a decline by $63.0 \%, 50.8 \%, 33.7 \%, 71.6 \%$, and $67.9 \%$ for FPase, pNPCase, CMCase, pNPGase and pNPXase activities, respectively, at $168 \mathrm{~h}$. However, this inhibition effect was not complete, for cellulase activities and secreted protein concentration were still raised at a very low speed as the fermentation progressed even in the presence of $2.92 \mathrm{~g} / \mathrm{L}$ glutamine. These findings indicate that the supplementation of glutamine into TMM slowed down the (hemi)cellulase production in T. reesei profoundly.

Moreover, glutamine with various concentrations were used as the sole nitrogen sources in TMM to produce cellulase in T. reesei (Fig. 2B). The (hemi)cellulase activities at $72 \mathrm{~h}$ first rose and then decreased as the concentration of glutamine increased (Fig. 2B). The highest enzyme activity occurred at $4 \mathrm{~g} / \mathrm{L}$ glutamine for FPase and CMCase, at $3 \mathrm{~g} / \mathrm{L}$ for pNPCase, and at 2-4 g/L for pNPGase and pNPXase. The effect of glutamine on the secreted protein concentration followed a similar trend to pNPGase and pNPXase activities. When the glutamine concentration was beyond $4 \mathrm{~g} / \mathrm{L}$ that was much lower than the total amount of nitrogen sources in TMM $(6 \mathrm{~g} / \mathrm{L})$, reduced cellulase activities were observed, implying that (hemi)cellulase production was more sensitive to glutamine excess than the nitrogen complex commonly used in TMM. Obviously, the impact of glutamine on cellulase production was concentration-dependent, serving as an inducer for cellulase production at low concentration but an inhibitor at high concentration. All these demonstrated that glutamine exerted a significant inhibition on cellulase biosynthesis under nitrogen excess, and the decreased cellulase production by the addition of glutamine in TMM (Fig. 1) was due to both surplus nitrogen source and glutamine inhibition. 

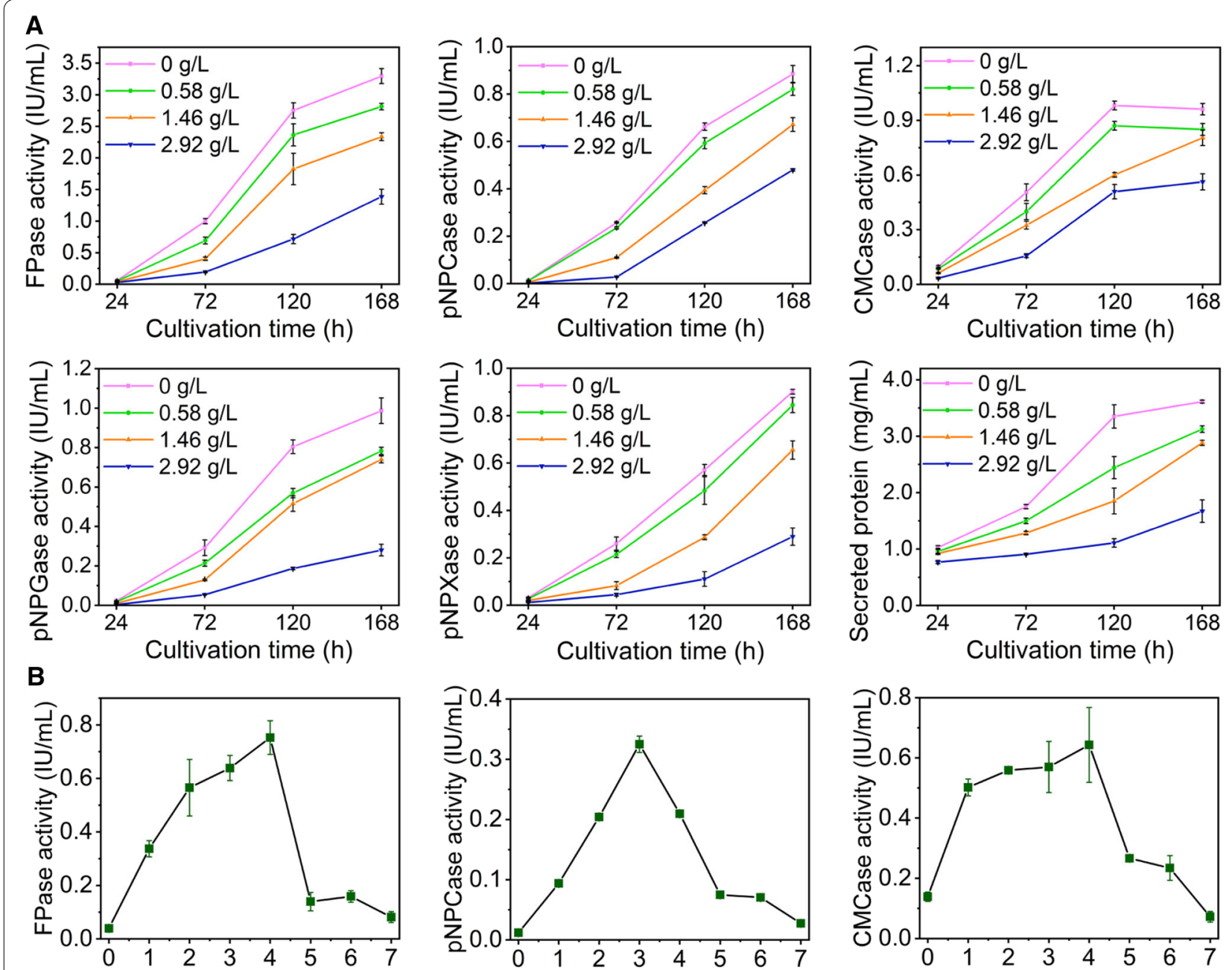

L-glutamine concentration ( $\mathrm{g} / \mathrm{L})$

L-glutamine concentration ( $\mathrm{g} / \mathrm{L})$

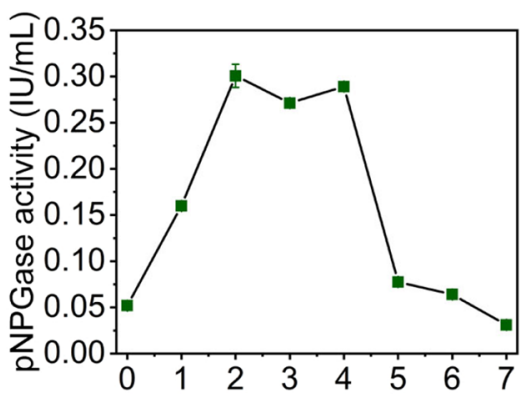

L-glutamine concentration ( $\mathrm{g} / \mathrm{L}$ )

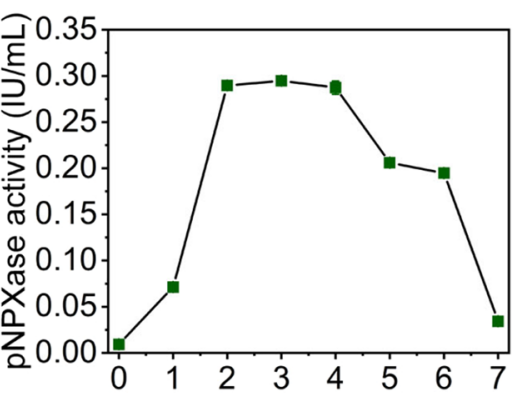

L-glutamine concentration ( $\mathrm{g} / \mathrm{L})$

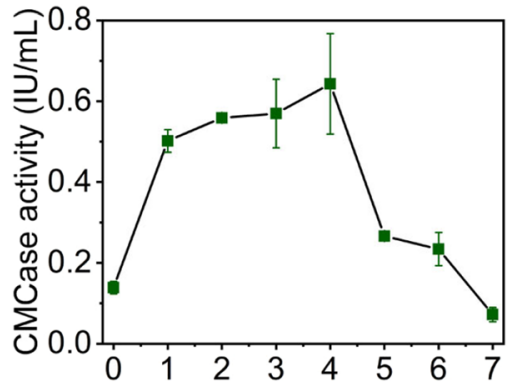

L-glutamine concentration $(\mathrm{g} / \mathrm{L})$

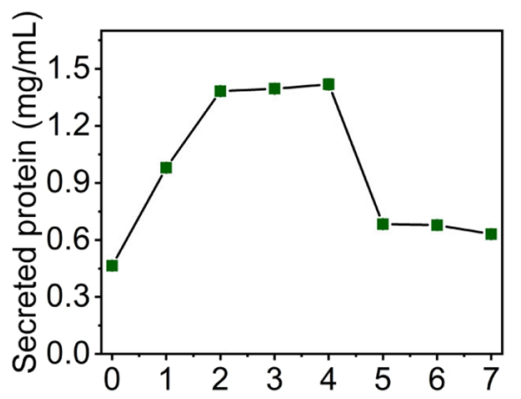

L-glutamine concentration ( $\mathrm{g} / \mathrm{L}$ )

Fig. 2 Effect of glutamine on (hemi)cellulase activities and protein secretion of T. reesei RUT-C30. A Enzyme activities of T. reesei RUT-C30 cultured in TMM with the supply of glutamine at varied concentrations. B Enzyme activities of T. reesei RUT-C30 cultured with different concentrations of glutamine as a sole nitrogen source. FPase: the filter paper activity; pNPCase: the CBH activity; CMCase: the CMC activity; pNPGase: the $\beta$-glucosidase activity; pNPXase: the $\beta$-xylosidase activity; Secreted protein: secreted protein concentration. Data are represented as the mean of three independent experiments and error bars express the standard

The phenotype effect of glutamine on $T$. reesei

Next, we investigated the effect of glutamine on growth, sporulation and morphology of $T$. reesei RUT-C30 grown on cellulose (Fig. 3). At $24 \mathrm{~h}$, no significant difference of growth was observed until the concentration of glutamine was increased to $2.92 \mathrm{~g} / \mathrm{L}$ compared to $T$. 

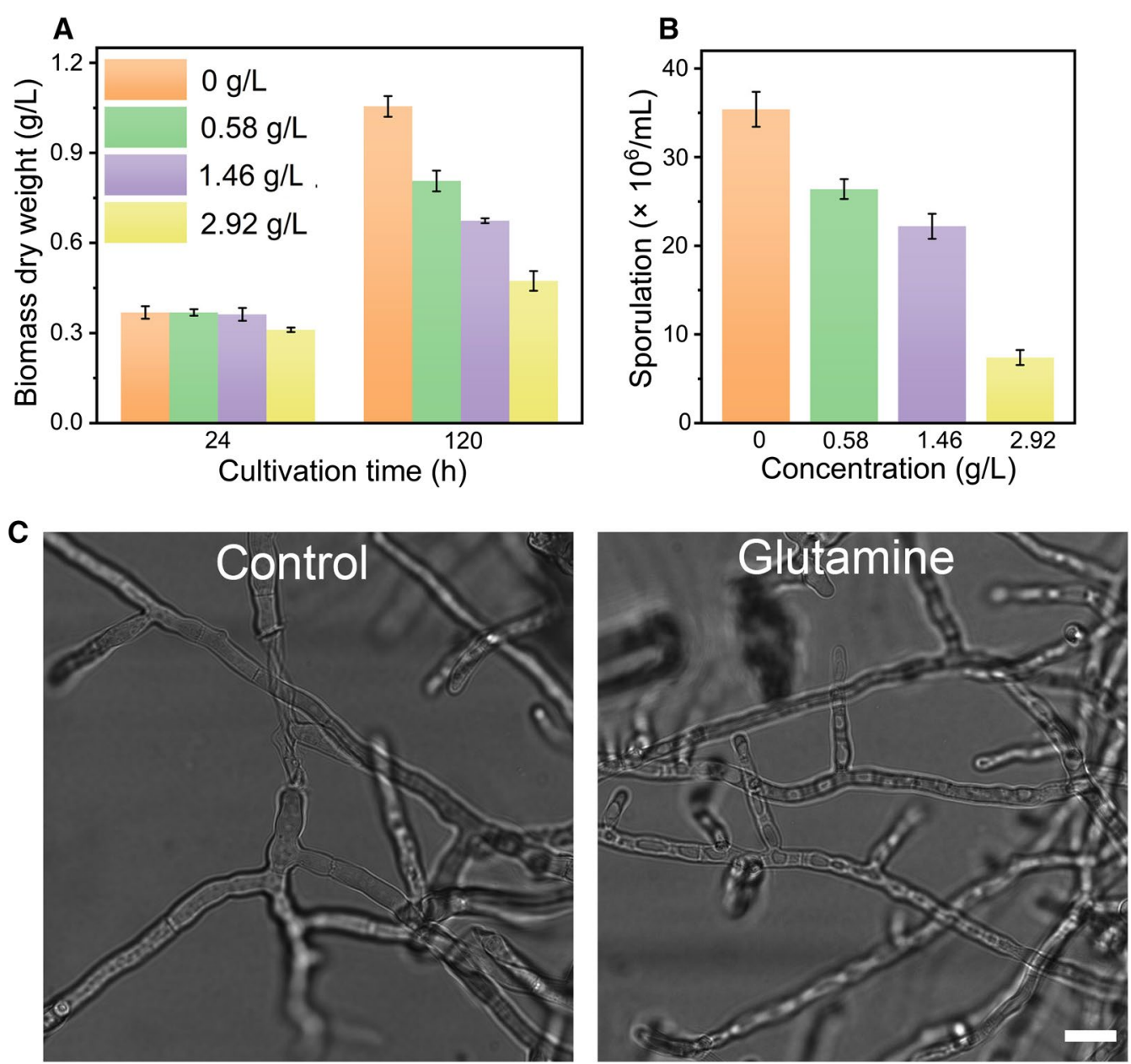

Fig. 3 Effect of glutamine on $\mathbf{A}$ growth, $\mathbf{B}$ sporulation at $120 \mathrm{~h}$ and $\mathbf{C}$ morphology at $24 \mathrm{~h}$ of $\mathrm{T}$. reesei RUT-C30 grown on TMM with the addition of glutamine at varied concentrations. The biomass dry weight per liter was calculated from the intracellular protein content based on $0.32 \mathrm{~g}$ of intracellular protein per $\mathrm{g}$ dry biomass. Error bars show the respective standard deviation of three biological replicates. Scale bar $=10 \mu \mathrm{m}$

reesei without glutamine. At $120 \mathrm{~h}$, the inhibition effect of glutamine became obvious with $23.5 \%, 36.1 \%$, and $55.1 \%$ growth reduction in the presence of $0.58 \mathrm{~g} / \mathrm{L}$, $1.46 \mathrm{~g} / \mathrm{L}$, and $2.92 \mathrm{~g} / \mathrm{L}$ glutamine, respectively (Fig. 3A). The sporulation ability of $T$. reesei was also retarded with the treatment of glutamine. The spore amount of $T$. reese $i$ was gradually decreased when the concentration of glutamine was increased (Fig. 3B). In the presence of $2.92 \mathrm{~g} / \mathrm{L}$ glutamine, the spore amount was only $20.9 \%$ of that of non-treated RUT-C30. Nevertheless, the morphology of RUT-C30 treated with $2.92 \mathrm{~g} / \mathrm{L}$ glutamine was similar to that of non-treated RUT-C30 (Fig. 3C), indicating that glutamine does not affect the morphology of $T$. reesei. These results suggested that the addition of glutamine impaired growth and sporulation of $T$. reesei on cellulose, but not its morphology.

\section{The effect of glutamine on the transcriptome of $T$. reesei}

Transcriptome sequencing analysis was carried out using $T$. reesei RUT-C30 cultured in TMM plus $2 \%$ cellulose with/without $2.92 \mathrm{~g} / \mathrm{L}$ glutamine for $24 \mathrm{~h}$ to understand how glutamine influences $T$. reesei at the transcriptional level. The sequences of the total reads were mapped to the reference genome of $T$. reesei RUT-C30 (https://www.ncbi.nlm.nih.gov/genome/ 323\%3fgenomeassembly_id\%3d49799) with coverage of $93.98-94.51 \%$. A total of 10,048 unique transcripts were detected (Additional file 1: Table S1). Genes were differentially expressed between the two strains when the average reads of the corresponding transcripts differed with $\mid \log _{2}$ Ratio $\mid \geq 1$ and adjusted $p$ values $\leq 0.05$. In the presence of glutamine, 1192 differentially expressed genes (DEGs) were obtained, of which 699 
were upregulated and 493 were downregulated (Additional file 2: Table S2).

Gene ontology (GO) functional enrichment analysis of these DEGs showed that the most enriched molecular function was "catalytic activity", which includes four enriched subcategories "hydrolase activity", "oxidoreductase activity", " $\beta$-glucosidase activity", and "xylanase activity" (Fig. 4). The other enriched molecular function was "cellulose binding". According to the analysis of the enriched cellular components, these DEGs were mainly distributed in extracellular region, nucleolus, mitochondrial matrix, peroxisome, microbody, and preribosome. For the enriched biological processes, the most enriched DEGs belong to "small molecule metabolic process" that includes two enriched subcategories "oxoacid metabolic process" and "alpha-amino acid catabolic process", "organonitrogen catabolic process" and "carbohydrate catabolic process", whose subcategory "polysaccharide catabolic process" was also enriched. The other two enriched biological processes were "cellulose catabolic process" and "hemicellulose catabolic process", which belong to "polysaccharide catabolic process". Most of DEGs in the enriched molecular functions " $\beta$-glucosidase activity", "xylanase activity", and "cellulose binding", and the enriched biological processes "cellulose catabolic process" and "hemicellulose catabolic process" were downregulated, which were in line with the sharply decreased cellulase production after the addition of glutamine
(Fig. 2A). Moreover, the enriched biological processes "organonitrogen catabolic process" and "alpha-amino acid catabolic process" indicate that the presence of glutamine affected the nitrogen metabolism of T. reese $i$ grown on cellulose.

The top 29 enriched KEGG pathways were obtained by KEGG pathway enrichment analysis of DEGs (Additional file 9: Figure S1), which were classified into four categories: "metabolic pathway", "biosynthesis of secondary metabolites", "biosynthesis of antibiotics", and "carbon metabolism". The addition of glutamine majorly affected pathways in "amino acid metabolism" and "carbohydrate metabolism". It seems that the metabolism of various amino acids including valine, leucine, isoleucine, tryptophan, cysteine, methionine, tyrosine and lysine was significantly changed by glutamine. (Hemi)cellulase-related genes belong to the enriched pathway "starch and sucrose metabolism".

\section{Most DEGs involved in the cellulase production were decreased in glutamine-treated $T$. reesei}

A total of 86 genes were known or predicted to be associated with (hemi)cellulase biosynthesis in $T$. ree$s e i$, of which 44 genes were DEGs with greatly reduced mRNA levels, except genes cel3g, M419DRAFT_93487 and M419DRAFT_6566 (Fig. 5 and Additional file 3: Table S3) that were upregulated. Particularly, the transcriptional levels of (hemi)cellulase genes including 2

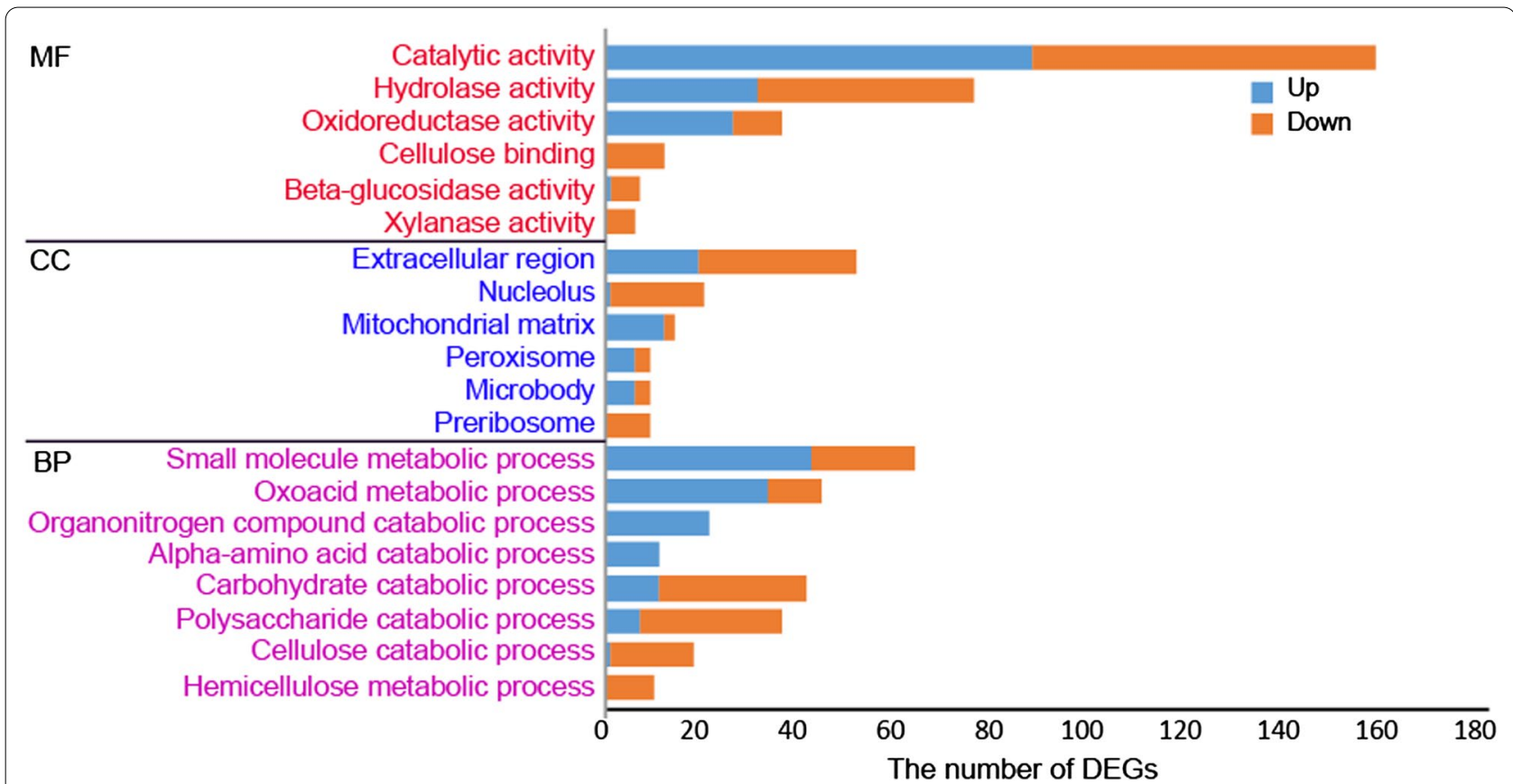

Fig. 4 Gene ontology (GO) functional enrichment analysis of DEGs. The y axis represents the name of the most enriched GOs that belong to different ontologies. MF: the molecular function; CC: the cellular component; BP: the biological process 


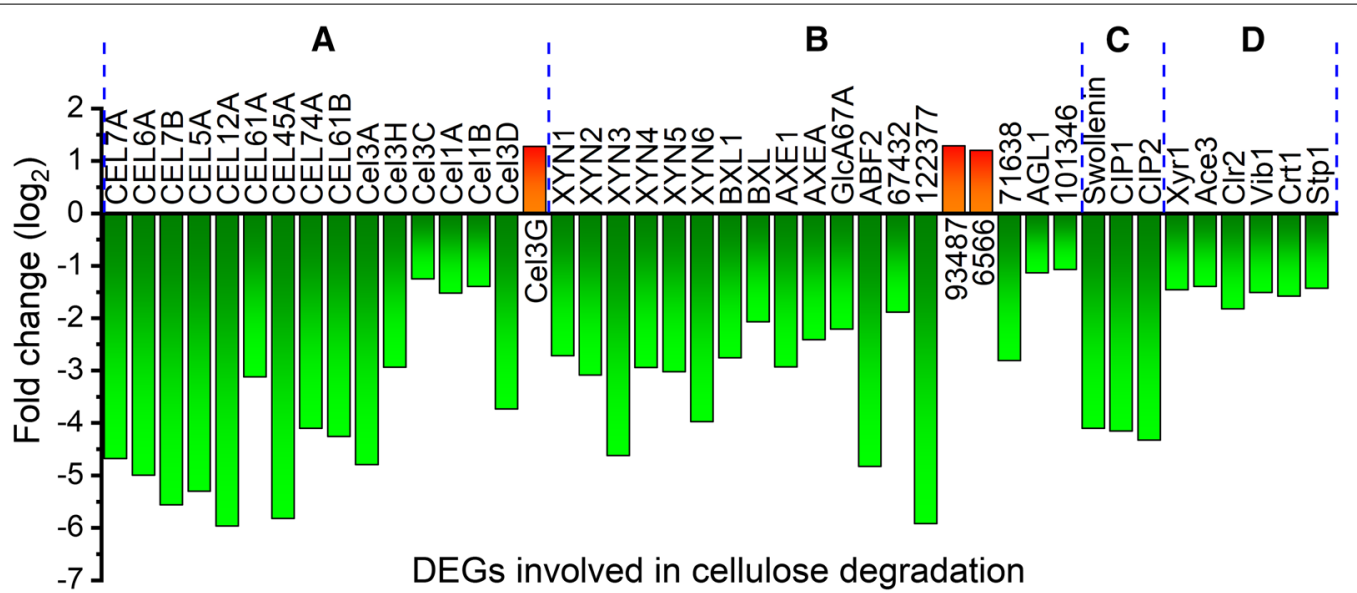

Fig. 5 Relative transcription levels of DEGs involved in cellulose degradation including $\mathbf{A}$ cellulase, $\mathbf{B}$ hemicellulase, $\mathbf{C}$ nonenzymatic cellulose attacking enzymes, and $\mathbf{D}$ transcriptional factors

cellobiohydrolases (CEL7A and CEL6A), 7 endoglucanases (CEL7B, CEL5A, CEL12A, CEL61A, CEL45A, CEL74A, and CEL61B), $6 \beta$-glucosidases (CEL3A, CEL3H, CEL3C, CEL1A, CEL1B, and CEL3D), 6 xylanases (XYN1, XYN2, XYN3, XYN4, XYN5, and XYN6), and two $\beta$-xylosidases (BXL1 and BXL) were all reduced markedly, matching well with the decreased (hemi)cellulase activities as observed above. Genes encoding the auxiliary proteins like swollenin [26], and the cellulose-induced proteins Cip1 and Cip2 [27], which have been reported to enhance cellulose degradation, were also down-expressed markedly. Furthermore, 6 cellulase transcription factors were significantly downregulated, including the well-known cellulase transcription activators Xyr1 [28], Ace3 [29], Clr2 [30], and Vib1 [31, $32]$, and MFS sugar transporters Crt1 and Stp1 [33, 34]. We are surprised to find that in contrast to most genes related to cellulase synthesis, the mRNA levels of cel3g, M419DRAFT_93487 and M419DRAFT_6566 were increased with the addition of glutamine. However, the reason behind this phenomenon is unknown as these three genes are lack of study, which is worthy of research in future study. This suggests that cellulase productions are subject to nitrogen regulation at the transcriptional level.

\section{The impact of glutamine on nitrogen metabolism of $T$. reesei}

15 DEGs are involved in ribosome biogenesis, all of which were downregulated except gene M419DRAFT_104236 (Additional file 4: Table S4). All these downregulated genes are related to the assembly and maturation of the large unit and small unit of ribosome. In contrast to the reduced mRNA levels of DEGs relevant to ribosomal biogenesis, all DEGs involved in amino acids were upregulated except that gene glutamate dehydrogenase (M419DRAFT_93755) was downregulated (Additional file 5: Table S5). Particularly, four of these DEGs are amino acid transporters, while the rest of genes are involved in branched or aromatic amino acid catabolic process.

In addition, a number of DEGs were found to be involved in nitrogen metabolism including the GS/ GOAT cycle and the GABA shunt. Glutamate dehydrogenase $(\mathrm{GDH})$ catalyzes the conversion of $\alpha$-ketoglutarate $(\alpha-K G)$ and ammonia $\left(\mathrm{NH}_{4}^{+}\right)$to glutamate. Then glutamine synthase (GS) uses glutamate and ammonia to synthesize glutamine. Both these genes were significantly downregulated as well as the ammonium permease (MepC) (Fig. 6), indicating glutamine biosynthesis was shut down in $T$. reesei treated with $2.92 \mathrm{~g} / \mathrm{L}$ glutamine. In contrast, the glutamine catabolism was enhanced, as shown by the increased mRNA levels of GOGAT and M419DRAFT_130207. The addition of glutamine also led to an upregulation of amino acid permeases, such as M419DRAFT_73503, M419DRAFT_77334, M419DRAFT_139450, M419DRAFT_100875 and M419DRAFT_24454. Meanwhile, glutamate biosynthesis was enhanced as demonstrated by the significantly increased mRNA levels of GOGAT, M419DRAFT_138585, M419DRAFT_115285, and PrnD and M419DRAFT_27041, which were responsible for the conversion of glutamine, arginine, isoleucine and proline to glutamate, respectively. All these suggested that the addition of glutamine led to a markedly decreased glutamine biosynthesis and the significantly increased glutamate biosynthesis and glutamine catabolism. Moreover, the transporters for different nitrogen sources including 


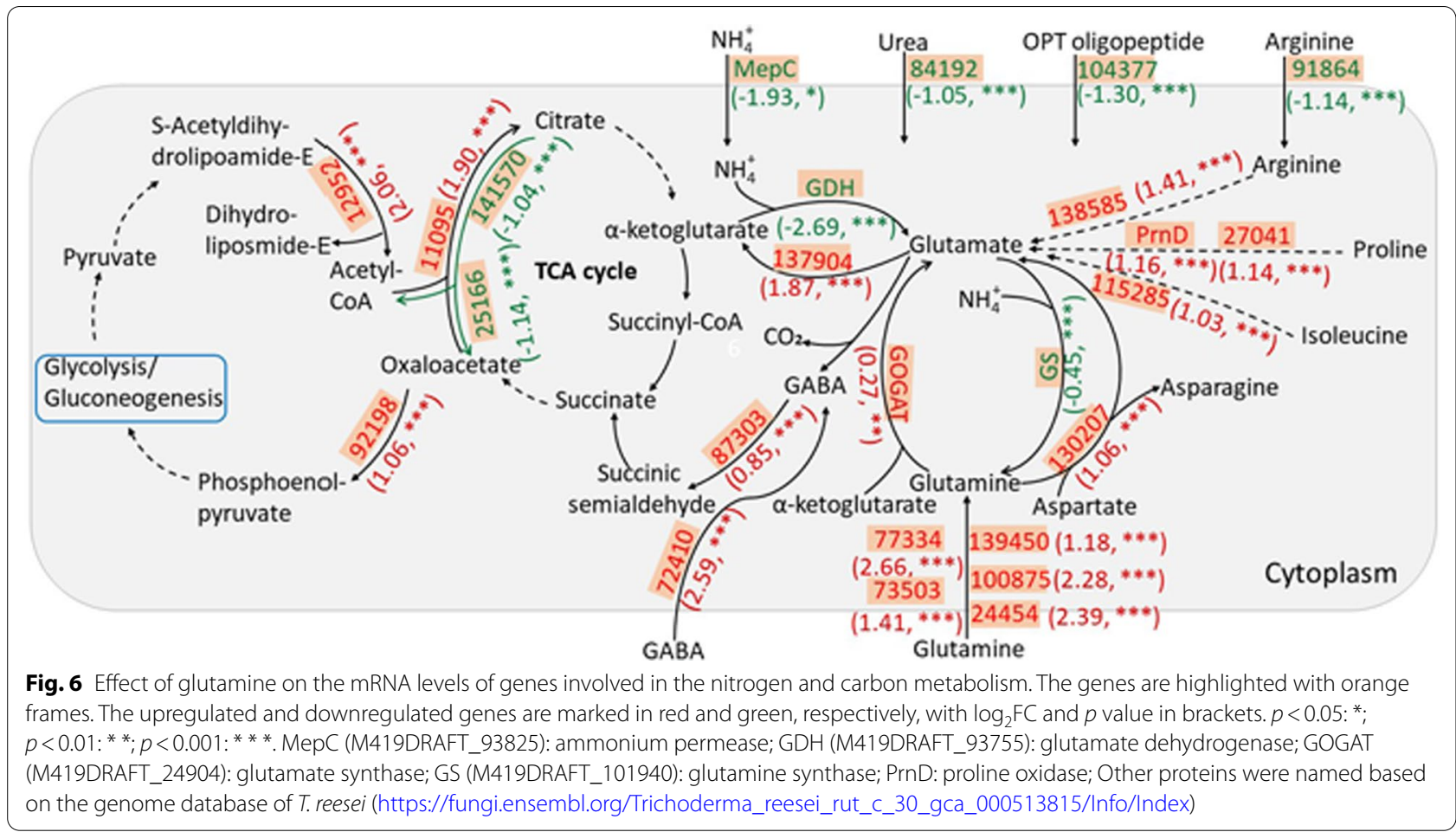

ammonium (MepC), urea (M419DRAFT_84192), oligopeptide (M419DRAFT_84192), arginine (M419DRAFT_91864) were dramatically downregulated, while transporters for amino acids and 4-aminobutanoic acid (GABA), were significantly upregulated. The upregulated expression of amino acid transporters might be involved in the uptake of glutamine. Gene encoding GABA transaminase (M419DRAFT_87303) was also increased. GABA is an intermediate metabolite in the GABA shunt, a metabolic pathway that bypasses two enzymatic steps of the tricarboxylic acid (TCA) cycle to produce succinate from $\alpha$-ketoglutarate via glutamate (Fig. 6).

As the GS/GOGAT cycle and the GABA shunt link primary nitrogen and carbon metabolism [1], the primary carbon metabolism might be also impacted by the addition of glutamine, as implied by the enriched glycolysis/ gluconeogenesis pathway (Additional file 9: Figure S1). Therefore, we also checked whether there were DEGs in TCA cycle and the glycolysis/gluconeogenesis pathway. 5 genes related to citrate cycle (TCA cycle, Krebs cycle) were differentially expressed. Acetyl-CoA was derived from pyruvate oxidation and then its acetyl group was transferred to oxaloacetate by citrate synthase to form citrate. The reaction rates of these two steps were speeded up as shown by the enhanced expression levels of M419DRAFT_12952 and M419DRAFT_11095. By contrast, the citrate lyase complex M419DRAFT_25166 and
M419DRAFT_141570 were downregulated, which catalyzed the decomposition of citrate. Besides, the mRNA level of M419DRAFT_92198, which was responsible for the conversion of oxaloacetate to phosphoenolpyruvate was upregulated. As TCA cycle was a hub coordinating matter and energy conversion, the addition of glutamine possibly changed the pattern of mass transfer and energy utilization. Taken together, the presence of glutamine in TMM affected notably the nitrogen metabolism significantly by decreasing ribosomal biogenesis, glutamine biosynthesis and other nitrogen transport while increasing glutamate biosynthesis, amino acid catabolism, and glutamine catabolism. Glutamine also posed an effect on the carbon metabolism including TCA cycle and the glycolysis/gluconeogenesis pathway.

\section{Genes ooc1 and ooc2 are associated with the cellulase repression impact of glutamine in $T$. reesei}

It is worth noting that the transcriptional level of the reported cellulose signaling related protein ooc1 (M419DRAFT_124152) [35] was increased remarkably, and its isoenzyme (M419DRAFT_131885), which was named ooc2 here, was the most upregulated DEG in the presence of glutamine (Additional file 2: Table S2). Therefore, we are curious on the role of ooc 1 and ooc2 in the responsiveness of $T$. reesei to glutamine. Genes ooc1 and ooc2 were deleted separately in $T$. reesei KU70, leading to recombinant strain $\Delta$ ooc1 and $\Delta$ ooc2, 
respectively. Strain KU70, a $k u 70$-deleted derivative of RUT-C30, was utilized as the parent strain for its high efficiency of gene targeting [36]. Interestingly, we found that the inhibition effect of glutamine on cellulase production in strain KU70 was not that significant as that in RUT-C30, though a mild reduction of cellulase production after the treatment of glutamine was still observed (Fig. 7). It seems that the absence of gene $k u 70$ renders the resistance of $T$. reesei RUT-C30 to glutamine. Further deletion of ooc1 and ooc2 individually brought back the cellulase inhibition effect of glutamine in strain KU70 (Fig. 7), indicating T. reesei RUT-C30 increased the expression of genes ooc1 and ooc2 to antagonize the cellulase-depression effect of glutamine, but failed. In particular, the inhibition effect of glutamine on cellulase production in strain $\Delta$ ooc2 was worse than that in strain $\Delta$ ooc1, although the abundance of ooc2 was far lower than that of $o o c 1$, as shown by that the FPKM of $o o c 2$ was only $0.21 \%$ of that of ooc1 in T. reesei under normal conditions (Additional file 2: Table S2). Moreover, in mutant strain $\Delta$ ooc12 with the double knockout of ooc1 and ooc2, the inhibition effect of glutamine on cellulase production was increased as compared to that in strain $\Delta$ ooc1, but was similar to that in strain $\Delta$ ooc2, demonstrating gene $o o c 1$ was a functional redundancy to gene $o o c 2$.

\section{The role of the TOR signaling pathway in glutamine-repressed cellulase production}

In mammals, yeasts and plants, the target-of-rapamycin (TOR) kinase signaling pathway was a central signaling hub integrating cell growth and metabolism [37-39]. It could be activated by amino acids, of which glutamine has been implicated in TOR activation [40]. Protein TOR contains conserved HEAT repeat, FAT, FKBP12/rapamycin binding (FRB), kinase, and FATC domains from the $\mathrm{N}$ to the $\mathrm{C}$ terminus, and forms two distinct physical and functional complexes, which are termed as TOR complex 1 (TORC1) and TORC2 (Fig. 8A). We wondered if the addition of glutamine into TMM could activate TOR and its related signaling pathways in $T$. reesei. Unexpectedly, transcriptional analysis showed that neither TOR nor the components of TORC1 and TORC2 were changed significantly after the treatment of glutamine for $24 \mathrm{~h}$ (Fig. 8A). Further analysis of their mRNA levels at $2 \mathrm{~h}$ and $8 \mathrm{~h}$ showed that TOR and Kog1 were significantly downregulated at $8 \mathrm{~h}$, while other genes did not change obviously at either timepoints (Fig. 8B). For genes associated with TOR signal pathways including

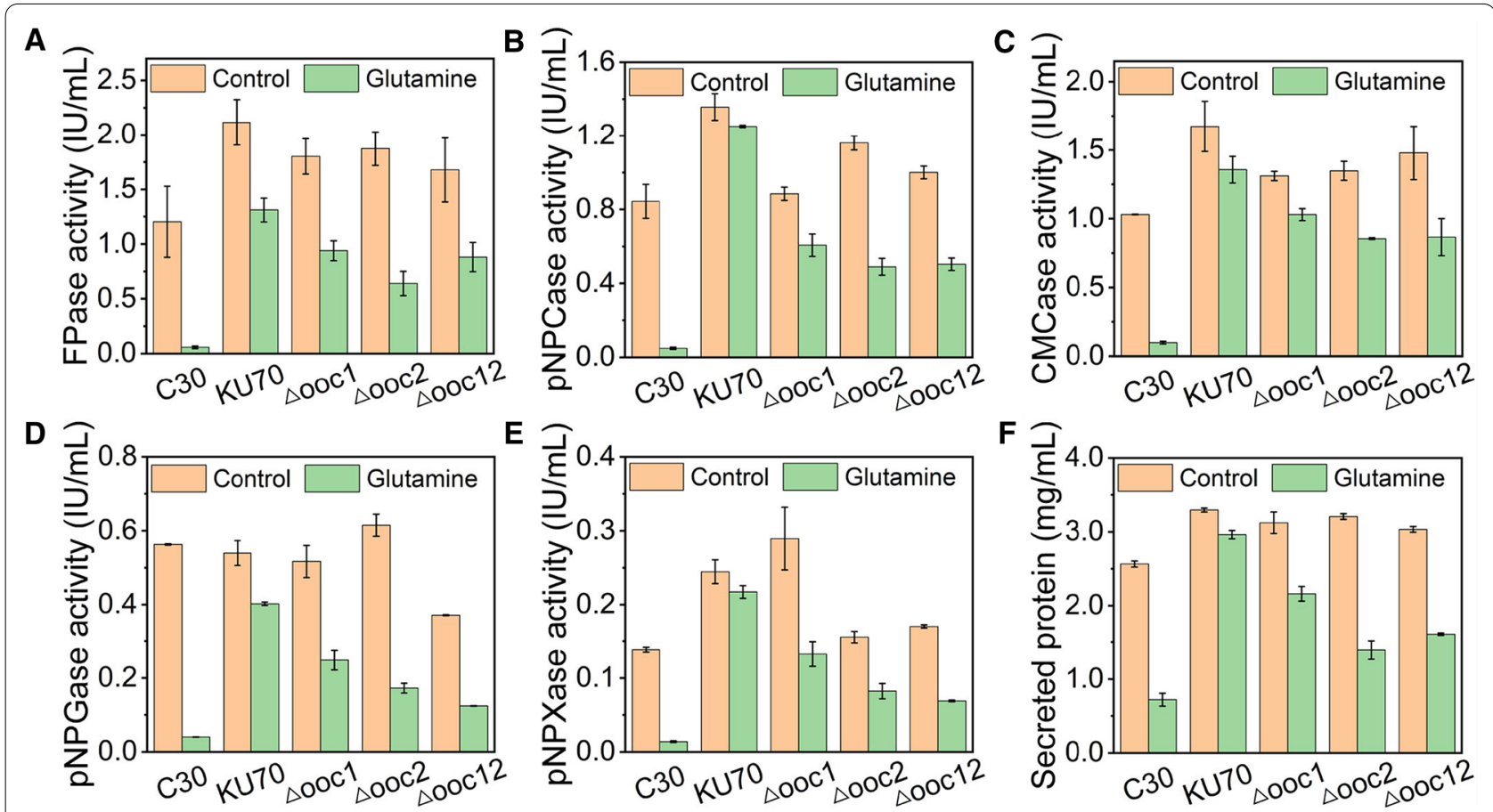

Fig. 7 Impact of glutamine on (hemi)cellulase activities and protein secretion of T. reesei KU70, $\triangle \mathrm{OoOC1}, \triangle \mathrm{Ooc} 2$, and $\triangle \mathrm{ooc} 12 \mathrm{cultured}$ in TMM + $2 \%$ cellulose + $2.92 \mathrm{~g} / \mathrm{L}$ glutamine for $120 \mathrm{~h}$. A FPase: the filter paper activity; B pNPCase: the CBH activity; C CMCase: the CMC activity; D pNPGase: the $\beta$-glucosidase activity; $\mathbf{E}$ pNPXase: the $\beta$-xylosidase activity; $\mathbf{F}$ Secreted protein: secreted protein concentration. Data are represented as the mean of three independent experiments and error bars express the standard 

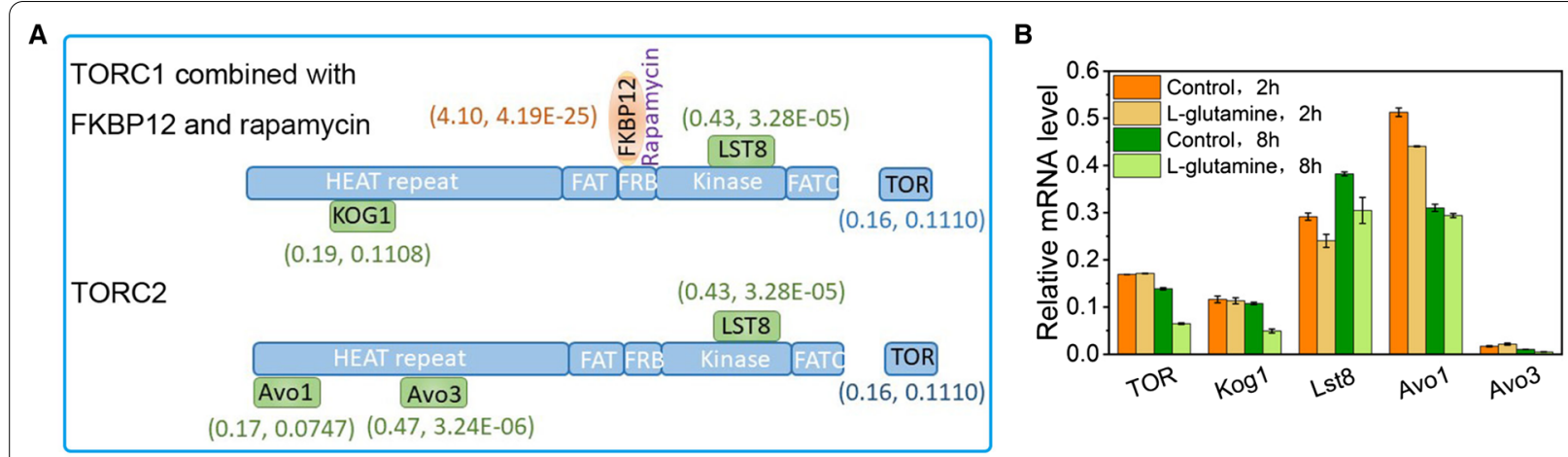

C

DEGs related to TOR signaling pathways in $T$. reesei

\begin{tabular}{lcccccc}
\hline \multirow{2}{*}{ Protein ID } & $\begin{array}{l}\text { T. reesei } \\
\text { length } \\
\text { (aa) }\end{array}$ & $\log _{2}$ FC & $p$ value & Name & Protein ID & Identity \\
\hline M419DRAFT_136493 & 534 & -1.66 & $1.02 \mathrm{E}-49$ & Msn2 & NP_013751.1 & $26.77 \%$ \\
& & & & Msn4 & NP_012861.1 & $24.70 \%$ \\
M419DRAFT_7110 & 684 & -1.44 & $7.47 \mathrm{E}-46$ & Rrn3 & NP_012797.1 & $25.60 \%$ \\
M419DRAFT_91864 & 512 & -1.14 & 6.93E-25 & Ssy1 & NP_010444.1 & $30.86 \%$ \\
M419DRAFT_97298 & 537 & -1.58 & 3.46E-38 & Ssy1 & NP_010444.1 & $26.63 \%$ \\
\hline
\end{tabular}

${ }^{a}$ Protein ID was assigned based on the genome database

(https://fungi.ensembl.org/Trichoderma_reesei_rut_c_30_gca_000513815/Info/Index)

${ }^{b}$ Protein ID was assigned based on the genome database (https://www.ncbi.nlm.nih.gov/)

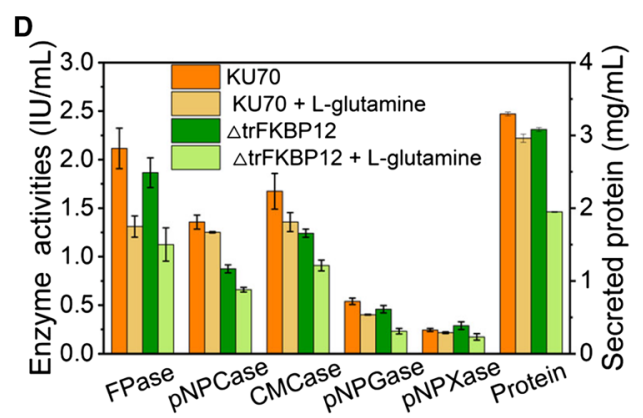

Fig. 8 Impact of glutamine on the TOR signaling pathways. A Relative transcription levels of trFKBP12, and TORC1/2 components in the presence of $2.92 \mathrm{~g} / \mathrm{L}$ glutamine for $24 \mathrm{~h}$. $\log _{2} \mathrm{FC}$ and $p$ value were in brackets, respectively. B mRNA level of TORC1 and TORC2 components at $2 \mathrm{~h}$ and $8 \mathrm{~h}$ in $T$. reesei with or without $2.92 \mathrm{~g} / \mathrm{L}$ glutamine. C DEGs related to TOR signaling pathways in T. reesei RUT-C30. D (Hemi)cellulase activities of strains KU70 and $\triangle$ trFKBP12 at $120 \mathrm{~h}$ cultured in TMM $+2 \%$ cellulose with/without $2.92 \mathrm{~g} / \mathrm{L}$ glutamine. Data are represented as the mean of three independent experiments and error bars express the standard

15 genes for ribosome biogenesis, 8 genes for cell cycle/ growth, 25 genes for nutrient uptake, 1 gene for stress, 5 genes for lipid metabolism, 6 genes for cell wall integrity, and 5 genes for autophagy [41] (Additional file 6: Table S6), only four genes (Rrn3, M419DRAFT_136493, M419DRAFT_91864 and M419DRAFT_97298) were differentially expressed (Fig. 8C). Rrn3 was a transcription initiation factor that regulated RNA polymerase (Pol) I-dependent gene expression during Pol I transcription initiation [42]. As Pol I was responsible for producing the $35 \mathrm{~S}$ rRNA precursor, the downregulated Rrn3 might lead to reduced ribosome biogenesis, which was confirmed by the downregulated expression of genes involved in ribosome biogenesis as we observed above. The downregulated M419DRAFT_136493, designated as stress response element binding protein, was homologous to Msn2 and Msn4, which were zinc finger transcription factors that regulate the general stress response, such as oxidative stress, heat shock, osmotic stress, high ethanol concentration and nutrient depletion in Saccharomyces cerevisiae [43]. M419DRAFT_91864 and M419DRAFT_97298 homologous to Ssy1 functioning as the primary amino acid receptor [44] were also downregulated. All these demonstrated that TOR and the corresponding kinase signaling pathways were not very sensitive to glutamine in $T$. reesei. By contrast, the cellular receptor of rapamycin trFKBP12 was noticeably upregulated by $2^{4.10}$ (17.14)-fold with $2.92 \mathrm{~g} / \mathrm{L}$ glutamine. To see whether trFKBP12 was involved in the negative impact of glutamine on cellulase production, the $\operatorname{trFKBP} 12$ deletion strain $\triangle \operatorname{trFKBP12}$ engineered in our previous study [41] was treated with glutamine. Similar to the deletion of genes ooc1 and ooc2, the knockout of trFKBP12 exacerbated the cellulase depression influence of glutamine (Fig. $8 \mathrm{D}$ ), suggesting that the upregulated expression of trFKBP12 by glutamine under nitrogen excess might also harnessed to antagonize the cellulase depression influence of glutamine. In summary, it seems that genes ooc1, ooc2, and trFKBP12 are all involved in the cellulase depression influence of glutamine, which might fight against the negative effect by the upregulation of these genes.

\section{Discussion}

To varying degrees, the supply of different nitrogen sources at equal amount to TMM culture medium inhibited cellulase production in T. reesei RUT-C30. Glutamate displayed the weakest inhibition effect on cellulase 
production, followed by ammonium sulfate, tryptone, urea, yeast extract and glutamine in ascending order. The cellulase inhibition was found regardless of nitrogen sources, while the inhibition degree was dependent on nitrogen types. This suggests that the cellulase inhibition was due to both the nitrogen excess induced by the addition of more nitrogen sources and the administered nitrogen source itself. Although the nitrogen content of different nitrogen sources varies greatly at $2.92 \mathrm{~g} / \mathrm{L}$, $40.0 \mathrm{mM}$ for glutamine, $97.2 \mathrm{mM}$ for urea, $44.2 \mathrm{mM}$ for ammonium sulfate, and $19.8 \mathrm{mM}$ for glutamate, there is no notable correlation between the nitrogen content and cellulase inhibition. For example, the inhibition effects of $2.92 \mathrm{~g} / \mathrm{L}$ glutamine and ammonium sulfate on cellulase production differed greatly, although they contained a similar nitrogen content. Despite of the most severe inhibition for glutamine on cellulase production, the nitrogen content of glutamine was between those of glutamate $(19.8 \mathrm{mM})$ and urea $(97.2 \mathrm{mM})$. Clearly, the cellulase inhibition effect was related to the nitrogen type rather than the nitrogen content. Glutamine possessed the strongest cellulase repression effect among all the tested nitrogen sources. Although both ammonium sulfate and glutamine are preferred nitrogen sources, glutamine displayed much stronger cellulase repression than that of ammonium sulfate, indicating that ammonium sulfate is a more suitable nitrogen source for cellulase production in T. reesei than glutamine. Meanwhile, glutamine and glutamate displayed a huge difference in the inhibition degree on cellulase production, though they can be converted to each other through the GS/GOGAT cycle in cells. It seems that glutamine may well be the metabolite effector in nitrogen repression of cellulase synthesis, similar to the role of glucose plays in CCR.

The presence of more nitrogen sources into TMM might lead to excess nitrogen, repressing cellulase production. During nitrogen sufficiency, glutamine as a strong nitrogen source for $T$. reesei might be utilized in preference to other nitrogen sources. Therefore, the presence of glutamine caused a significant change on nitrogen transport and metabolism in $T$. reesei. We can see the supply of glutamine shut down the transport of other nitrogen sources including ammonium, urea, oligopeptide (M419DRAFT_84192), and arginine, but enhanced its transport through the upregulation of amino acid transporters (Fig. 6). Particularly, the assimilation of ammonium was reduced significantly. Meanwhile, the presence of glutamine in TMM affected notably the nitrogen metabolism by repressing ribosomal biogenesis and glutamine biosynthesis while enhancing glutamate biosynthesis, amino acid catabolism, and glutamine catabolism.
On the other hand, glutamine is commonly thought to be the pivotal metabolite for sensing cellular nitrogen sufficiency and activating nitrogen metabolite repression [45]. Filamentous ascomycetes possess three important nitrogen regulators, namely, the activator AreA, and two repressors AreB and NmrA [7, 46]. AreA activates a broad range of genes involved in the utilization of secondary nitrogen sources in the absence of glutamine and ammonium, while AreB regulates AreA activity to repress AreA-dependent nitrogen catabolic genes under carbon-limiting conditions. Another level of regulation of AreA activity involves its interaction with the co-repressor NmrA. In addition, NmrA appears to modulate AreA and AreB activities in response to the carbon status of the cell. All these genes were reduced significantly after the addition of glutamine (Additional file 7: Table S7), though they were not DEGs according to the stringent standard we used, indicating that nitrogen metabolite repression occurred after the treatment of glutamine.

In the presence of glutamine, T. reesei adjusts its metabolism for a high rate of glycolysis and directs carbon flux to respiration and fermentation for biosynthesis and energy production, while genes involved in utilization of alternative carbon sources are repressed in a Cre1-dependent manner as suggested by the upregulated expression of the carbon catabolite repressor Cre1 (Additional file 7: Table S7). Cre1 was shown to modulate genes encoding amino acid transporters $T$. reesei [47], and play a role in nitrogen catabolite repression in $A$. nidulans [48], suggesting that the role of Cre1 is not limited to CCR but has a cell-wide role to ensure fungal growth and survival in the presence of varied carbon and nitrogen sources. Furthermore, Vib1 was significantly reduced (Fig. 5), in agreement with that gene deletion of $v i b 1$ in strain RUT-C30 decreased cellulase expression [31]. In Neurospora crassa, Vib1 does not directly modulate cellulase gene expression, but impacts the expression level of an essential cellulase regulator CLR2 [49] which was downregulated significantly in the presence of glutamine in our study (Fig. 5). Vib1 functions in repressing both glucose signaling and CCR under carbon-limited conditions, enabling a proper cellular response for plant biomass deconstruction and utilization. Vib1 is also required for extracellular protease secretion in response to both carbon and nitrogen starvation in $N$. crassa [50]. The effect of glutamine on the mRNA levels of these genes relevant to both nitrogen and carbon metabolism implicated that glutamine impacted not only the nitrogen metabolism, but also the carbon metabolism for cellulase production in T. reesei.

Filamentous fungi require sufficient nutrient availability to meet biological demand for cell growth. Glucose and glutamine are two primary carbon/nitrogen sources 
of the TCA cycle, macromolecule production, and ATP generation for proliferating cells [51]. The addition of glutamine broke the previous equilibrium of TCA cycle and led to an increased synthesis of $\alpha$-ketoglutarate and succinic semialdehyde (Fig. 6). Besides, nitrogen catabolite repression (NCR) was activated in the presence of glutamine, which represses the expression of genes for the use of alternative and less preferred nitrogen sources like ammonium, urea, OPT oligopeptide and arginine (Fig. 6). It seems that NCR mediated by glutamine has a negative effect on cellulase production, similar to that caused by CCR in the presence of glucose. When cellulose was the sole carbon source, the decreased synthesis of cellulase at both transcription and protein levels led to a short supply of glucose, which contributed to the inhibition of the growth and sporulation of $T$. reesei (Fig. 3).

Genes ooc1 and ooc2 are next to each other and oriented tail to tail in T. reesei genome. They are small proteins with 101 and 104 amino acids separately and are homologous to each other with $43 \%$ sequence identity. Both of them contain signal peptides for secretion, suggesting that they could be secreted to the extracellular space. When T. reesei QM9414 was cultured at $\mathrm{pH} 6.0$ induced by cellulose, the expression levels of ooc1 and ooc 2 were also increased compared to that at $\mathrm{pH} 3.0$ and $\mathrm{pH} 4.5$, indicating that ooc 1 and ooc2 were $\mathrm{pH}$ responsive [52]. It seemed that ooc1 and ooc2 are functionally equivalent. Compared to the parental strain QM9414, ooc1 was upregulated in $T$. reesei $\Delta p h l p 1$ (phosducinlike protein) [53], $\Delta p k a c 1$ (protein kinase) [54] or $\Delta c r e 1$ [54] strains in darkness. In Trichoderma harzianum T34, ooc1 was induced during its interactions with Pythium ultimum when nox1 was overexpressed [55]. In this study, they were among the most upregulated DEGs in the presence of glutamine (Additional file 2: Table S2), whose knockout worsened the cellulase inhibition effect of glutamine in strain KU70 (Fig. 7). It seems that T. reesei RUT-C30 increased the expression of genes ooc1 and $o o c 2$ to antagonize the cellulase-depression effect of glutamine. All these demonstrate that gene ooc 1 and ooc 2 in T. reesei RUT-C30 were highly responsive to various signals in the environment.

The TOR kinase, a central regulator of nutrient response, plays an important role in cell growth and metabolism and could be activated by glutamine [56]. However, TOR and TOR complexes were not differentially expressed with the addition of glutamine at $2 \mathrm{~h}, 8 \mathrm{~h}$ and $24 \mathrm{~h}$, except that TOR and Kog1 were reduced at $8 \mathrm{~h}$ (Fig. 8B). By contrast, the mRNA level of $\operatorname{trFKBP12}$ was increased remarkably. This was similar to what we found previously that genes related to TOR signaling pathways were not changed significantly but $\operatorname{trFKBP} 12$ was significantly upregulated by rapamycin in $T$. reesei grown on cellulose condition [41]. Nevertheless, there were still several genes in the TOR signaling pathways affected by glutamine, including the upregulated expression of the cellular receptor of rapamycin $\operatorname{tr} F K B P 12$, and the downregulated expression of transcription initiation factor Rrn3, stress-responding transcription factors Msn2 and Msn4, as well as the primary amino acid receptor Ssy1. In addition, the deletion of $\operatorname{trFKBP} 12$ reinforced the inhibition of glutamine on cellulase synthesis, showing that gene $\operatorname{trFKBP} 12$ is related to the glutamine-inhibited cellulase production in $T$. reesei.

\section{Conclusion}

Using T. reesei as an example, we first studied the effect of glutamine on cellulase-producing fungi under cellulose condition, including cellulase production, cell growth, sporulation, mycelium morphology and transcriptome. Under nitrogen excess condition, glutamine displayed the strongest inhibition effect on cellulase production, followed by ammonium sulfate, tryptone, urea, yeast extract and glutamine in descending order. Cellulase production was declined and the growth as well as sporulation were impaired with the addition of glutamine, while the mycelium morphology was not changed. Further RNAseq analysis showed that genes associated with the cellulase production were decreased severely at the mRNA level in the presence of glutamine. Moreover, glutamine exerted a remarkable change on the transcriptional levels of genes related to nitrogen metabolism, such as the decreased expression of genes taking part in non-glutamine nitrogen transport, ribosomal biogenesis and glutamine biosynthesis, and the enhanced expression of genes associated with glutamate biosynthesis, amino acid catabolism, and glutamine catabolism. Genes ooc1, ooc2 and $\operatorname{trFKBP} 12$ are associated with the cellulase repression impact of glutamine in $T$. reesei. All together, we found that glutamine is probably the metabolite effector in nitrogen repression of cellulase synthesis by significantly changing nitrogen transport and metabolism, which is facilitated by genes $o o c 1, o o c 2$, and $\operatorname{trFKBP} 12$. These findings provide a comprehensive understanding of the regulatory mechanism of nitrogen in cellulase production in filamentous fungi, which would help in establishing optimal fermentation strategies for better cellulase production in industry.

\section{Methods}

Microbial strains, plasmids and cultivation conditions Escherichia coli DH5 $\alpha$ was used as the cloning host for plasmid construction. Agrobacterium tumefaciens AGL-1 was used as a T-DNA donor for fungal transformation. T. reesei RUT-C30 (CICC 13052, ATCC 56765) was purchased from China Center of Industrial Culture 
Collection. T. reesei KU70, where $k u 70$ was deleted in RUT-C30 [57], was provided friendly by Professor Wei Wang from East China University of Science and Technology. E. coli DH5 $\alpha$ and A. tumefaciens AGL-1 were cultivated in Luria-Bertani (LB) with $220 \mathrm{rpm}$ at $37^{\circ} \mathrm{C}$ and $28{ }^{\circ} \mathrm{C}$, respectively. T. reesei were grown on potato dextrose agar (PDA) plates for conidia production and in TMM [58] with $2 \%(\mathrm{w} / \mathrm{t})$ cellulose for cellulase production at $28^{\circ} \mathrm{C}$ with $220 \mathrm{rpm}$. The TMM medium was as followed: Tryptone, $0.75 \mathrm{~g} / \mathrm{L}$; Yeast extract, $0.25 \mathrm{~g} / \mathrm{L}$; Urea, $1.00 \mathrm{~g} / \mathrm{L} ;\left(\mathrm{NH}_{4}\right)_{2} \mathrm{SO}_{4}, 4.00 \mathrm{~g} / \mathrm{L} ; \mathrm{KH}_{2} \mathrm{PO}_{4}, 6.59 \mathrm{~g} / \mathrm{L} ;$ Maleic acid, $11.6 \mathrm{~g} / \mathrm{L} ; \mathrm{FeSO}_{4} * 7 \mathrm{H}_{2} \mathrm{O}, 0.005 \mathrm{~g} / \mathrm{L} ; \mathrm{MnSO}_{4}{ }^{*} \mathrm{H}_{2} \mathrm{O}$, $0.0016 \mathrm{~g} / \mathrm{L} ; \mathrm{ZnSO}_{4} * 7 \mathrm{H}_{2} \mathrm{O}, 0.0014 \mathrm{~g} / \mathrm{L} ; \mathrm{CoCl}_{2} * 6 \mathrm{H}_{2} \mathrm{O}$, $0.002 \mathrm{~g} / \mathrm{L} ; \mathrm{MgSO}_{4}, 0.60 \mathrm{~g} / \mathrm{L} ; \mathrm{CaCl}_{2}, 0.60 \mathrm{~g} / \mathrm{L}$; Tween 80 , $0.186 \mathrm{ml} / \mathrm{L}$ [58]. When glutamine was the sole nitrogen source, different concentrations of glutamine were used to replace all the nitrogen sources of TMM. All chemicals used in this research were ordered from Sigma-Aldrich, USA.

\section{Shake flask cultivation}

Five percent $\left(\mathrm{v} / \mathrm{v}, 10^{7} / \mathrm{mL}\right)$ conidia of $T$. reesei were inoculated into $10 \mathrm{~mL}$ sabouraud dextrose broth (SDB) and cultured at $28{ }^{\circ} \mathrm{C}$ with $200 \mathrm{rpm}$ for 2 days. $5 \mathrm{~mL}$ pre-grown mycelia were inoculated into $50 \mathrm{~mL}$ TMM media ( $\mathrm{pH}$ 6) plus $2 \%$ cellulose with different concentrations of glutamine and incubated at $28{ }^{\circ} \mathrm{C}$ with $200 \mathrm{rpm}$ for 7 days. The stock solution of glutamine $(100 \mathrm{~g} / \mathrm{L})$ was prepared in water. Samples were taken at indicated timepoints for (hemi)cellulase activity assay, confocal observation, biomass dry weight measurement, and RNA-seq analysis. The samples of $T$. reesei culture collected above were centrifuged at $8000 \mathrm{rpm}$ for $30 \mathrm{~min}$ to remove the cell pellets, leading to the supernatants for (hemi) cellulase activities assay as described in our previous research [59-62]. If required, samples were centrifuged at $8000 \mathrm{rpm}$ for $30 \mathrm{~min}$ to isolate the mycelia from the supernatant.

For T. reesei grown in TMM with the addition of various nitrogen sources as indicated in the text, $2.92 \mathrm{~g} / \mathrm{L}$ nitrogen source was added into TMM. For T. reesei grown in culture medium using different nitrogen sources as the sole nitrogen source, all the nitrogen sources of TMM were removed and $4 \mathrm{~g} / \mathrm{L}$ each nitrogen source was added.

\section{Measurement of the biomass dry weight of $T$. reesei grown on cellulose}

The biomass of $T$. reesei grown in $\mathrm{TMM}+2 \%$ cellulose with and without glutamine was indirectly determined by the amount of intracellular protein $[63,64]$. In brief, harvested mycelia were suspended in $1 \mathrm{M} \mathrm{NaOH}$ and incubated for $2 \mathrm{~h}$ with frequent vortex. Then the protein concentration of the supernatant of the suspension was determined by the Modified BCA Protein Assay Kit (Sangon Biotech, Shanghai, China). The biomass dry weight was calculated assuming an average content of $0.32 \mathrm{~g}$ intracellular protein per $\mathrm{g}$ of dry cell mass.

\section{Analysis methods}

(Hemi)cellulase activity assay, confocal imaging, spore counting, RNA-seq analysis, and RT-PCR were performed as described in our previous research [41, 65]. T. reesei RUT-C30 cultured for $24 \mathrm{~h}$ with or without $2.92 \mathrm{~g} / \mathrm{L}$ glutamine were utilized for RNA-seq. Especially, confocal images of $T$. reesei were taken using a confocal microscope SP8 (Leica, Germany) with a $100 \times$ oil immersion objective. The spores were counted by a hemocytometer under a confocal microscope SP8 with a $20 \times$ oil immersion objective. The relative mRNA level was normalized using the housekeeping gene sar1 [66]. All the primers used in the text are described in Additional file 8: Table S8.

\section{Deletion of genes ooc1 and ooc2 in T. reesei KU70}

The upstream and downstream sequences $(\sim 1500 \mathrm{bp})$ of gene $o o c 1$, ooc2, and $o o c 1$ and $o o c 2$ were separately amplified by PCR using genomic DNA of T. reesei KU70 as a template, and cloned into plasmid pXBthg at XhoI and at BamHI using ClonExpress ${ }^{\mathrm{TM}}$ II One Step Cloning Kit (Vazyme, China), leading to plasmids pXBthg-ooc1, pXBthg-ooc2, and pXBthg-ooc12, respectively. Genes ooc1 and ooc2 can be deleted simultaneously as they are next to each other in $T$. reesei genome. The resulting plasmids pXBthg-ooc1, pXBthg-ooc2, and pXBthgooc12 were individually transformed into $T$. reesei KU70 separately by the Agrobacterium tumefaciens-mediated transformation (AMT) method using hygromycin B as a marker [67], yielding the deletion strains $\triangle$ ooc1, $\triangle$ ooc2, and $\triangle$ ooc12, respectively. The primers used were listed in Additional file 8: Table S8 and the verification of gene deletion in the recombinant strains was confirmed by PCR (Additional file 9: Figure S2) and sequencing.

\section{Abbreviations}

CCR: Carbon catabolite repression; NCR: Nitrogen catabolite repression; TMM: Trichoderma Minimal medium; GDH: Glutamate dehydrogenase; a-KG: a-ketoglutarate; $\mathrm{NH}_{4}{ }^{+}$: Ammonia; GS: Glutamine synthase; MepC: Ammonium permease; pNPGase: The $\beta$-glucosidase activity; pNPCase: The CBH activity; 
CMCase: The CMC activity; FPase: The filter paper activity; pNPXase: The $\beta$-xylosidase activity; AMT: Agrobacterium-mediated fungal transformation; SDB: Sabouraud dextrose broth; PDA: Potato dextrose agar.

\section{Supplementary Information}

The online version contains supplementary material available at https://doi. org/10.1186/s13068-021-02046-1.

Additional file 1: Table S1. The comparative transcriptome in T. reesei RUT-C30 cultured in TMM with/without the addition of glutamine.

Additional file 2: Table S2. Total DEGs in T. reesei RUT-C30 cultured in TMM with the addition of glutamine.

Additional file 3: Table S3. Genes involved in (hemi)cellulase production in T. reesei RUT-C30.

Additional file 4: Table S4. DEGs related to "ribosome biogenesis" in T. reesei RUT-C30 cultured in TMM with the addition of glutamine.

Additional file 5: Table S5. DEGs involved in amino acids in T. reesei RUTC30 cultured in TMM with the addition of glutamine.

Additional file 6: Table S6. Genes involved in TOR signal pathways in T. reesei RUT-C30.

Additional file 7: Table S7. Genes involved in nitrogen and carbon catabolite repression in T. reesei RUT-C30.

Additional file 8: Table S8. Primers for gene cloning, PCR confirmation and $\mathrm{gPCR}$.

Additional file 9: Figure S1. Kyoto Encyclopedia of Genes and Genomes (KEGG) enrichment analysis of DEGs. The y axis represents the name of the most enriched pathways. Figure S2. PCR confirmation of recombinant $T$. reesei strains $\triangle$ ooc1, $\triangle$ ooc2, and $\triangle$ ooc 12 .

\section{Acknowledgements}

Not applicable.

\section{Authors' contributions}

APP, ZL, and FL conceived and designed the study. APP carried out the majority of the experiments. FZ, XH, HW and YL carried out some experiments on T. reesei cultivation, enzyme activity, and confocal imaging, respectively. ZZ provided the plasmid pXBthg. FGW and BZL helped analyze the data. APP and FL analyzed the data and drafted the manuscript. All authors read and approved the final manuscript.

\section{Funding}

This work was supported by grants from the National Natural Science Foundation of China (32170072) and the Fundamental Research Funds for the Central Universities.

\section{Availability of data and materials}

The data sets supporting the conclusions of this article are included in the article and its Additional files.

\section{Declarations}

Ethical approval and consent to participate

Not applicable.

\section{Consent for publication}

Not applicable.

\section{Competing interests}

The authors declare that they have no competing interests.

\section{Author details}

${ }^{1}$ State Key Laboratory of Bioelectronics, School of Biological Science and Medical Engineering, Southeast University, Nanjing, China. ${ }^{2}$ Key Laboratory of Systems Bioengineering (Ministry of Education), School of Chemical Engineering and Technology, Tianjin University, Tianjin, China. ${ }^{3}$ Key Laboratory of Synthetic Biology, Institute of Plant Physiology and Ecology, Shanghai Institutes for Biological Sciences, Chinese Academy of Sciences, Shanghai, China.

Received: 8 July 2021 Accepted: 23 September 2021

Published online: 13 October 2021

\section{References}

1. Xiong Y, Wu VW, Lubbe A, Qin L, Deng S, Kennedy M, et al. A fungal transcription factor essential for starch degradation affects integration of carbon and nitrogen metabolism. PLoS Genet. 2017;13(5):e1006737.

2. Marzluf GA. Genetic regulation of nitrogen metabolism in the fungi. Microbiol Mol Biol Rev. 1997;61(1):17-32.

3. Wong $\mathrm{KH}$, Hynes MJ, Davis MA. Recent advances in nitrogen regulation: a comparison between Saccharomyces cerevisiae and filamentous fungi. Eukaryot Cell. 2008;7(6):917-25.

4. Huberman LB, Wu VW, Kowbel DJ, Lee J, Daum C, Grigoriev IV, et al. DNA affinity purification sequencing and transcriptional profiling reveal new aspects of nitrogen regulation in a filamentous fungus. Proc Natl Acad Sci US A. 2021:118(13):e2009501118.

5. Milhomem Cruz-Leite VR, Salem-Izacc SM, Novaes E, Neves BJ, de Almeida BW, Ohara Souza Silva L, et al. Nitrogen catabolite repression in members of Paracoccidioides complex. Microb Pathog. 2020;149:104281.

6. Jackson CA, Castro DM, Saldi GA, Bonneau R, Gresham D. Gene regulatory network reconstruction using single-cell RNA sequencing of barcoded genotypes in diverse environments. Elife. 2020;9:e51254.

7. Tudzynski B. Nitrogen regulation of fungal secondary metabolism in fungi. Front Microbiol. 2014;5:656.

8. Okal EJ, Aslam MM, Karanja JK, Nyimbo WJ. Mini review: advances in understanding regulation of cellulase enzyme in white-rot basidiomycetes. Microb Pathog. 2020;147:104410.

9. Chaabouni SE, Belguith H, Hassairi I, Mrad K, Ellouz R. Optimization of cellulase production by Penicillium occitantis. Appl Microbiol Biotechnol. 1995;43(2):267-9.

10. Maeda RN, da Silva MMP, Santa Anna LMM, Pereira N. Nitrogen source optimization for cellulase production by Penicillium funiculosum, using a sequential experimental design methodology and the desirability function. Appl Biochem Biotechnol. 2010;161(1):411-22.

11. Mihlan M, Homann V, Liu TW, Tudzynski B. AREA directly mediates nitrogen regulation of gibberellin biosynthesis in Gibberella fujikuroi, but its activity is not affected by NMR. Mol Microbiol. 2003;47(4):975-91.

12. Gardiner DM, Kazan K, Manners JM. Novel genes of Fusarium graminearum that negatively regulate deoxynivalenol production and virulence. Mol Plant Microbe Interact. 2009:22(12):1588-600.

13. Ehrlich KC, Cotty PJ. Variability in nitrogen regulation of aflatoxin production by Aspergillus flavus strains. Appl Microbiol Biotechnol. 2002;60(1-2):174-8

14. Qian Y, Sun Y, Zhong L, Sun N, Sheng Y, Qu Y, et al. The GATA-Type transcriptional factor Are1 modulates the expression of extracellular proteases and cellulases in Trichoderma reesei. Int J Mol Sci. 2019;20(17):4100.

15. Lockington RA, Rodbourn L, Barnett S, Carter CJ, Kelly JM. Regulation by carbon and nitrogen sources of a family of cellulases in Aspergillus nidulans. Fungal Genet Biol. 2002;37(2):190-6.

16. Rodriguez-Gomez D, Hobley TJ. Is an organic nitrogen source needed for cellulase production by Trichoderma reesei Rut-C30? World J Microbiol Biotechnol. 2013;29(11):2157-65.

17. Callow NV, Ray CS, Kelbly MA, Ju LK. Nutrient control for stationary phase cellulase production in Trichoderma reesei Rut C-30. Enzyme Microb Technol. 2016:82:8-14.

18. Yoav S, Salame TM, Feldman D, Levinson D, loelovich M, Morag E, et al. Effects of crel modification in the white-rot fungus Pleurotus ostreatus PC9: altering substrate preference during biological pretreatment. Biotechnol Biofuels. 2018;11:212.

19. Hassan L, Lin L, Sorek H, Sperl LE, Goudoulas T, Hagn F, et al. Crosstalk of cellulose and mannan perception pathways leads to inhibition of cellulase production in several filamentous fungi. mBio. 2019;10(4):e00277-19.

20. Wu VW, Thieme N, Huberman LB, Dietschmann A, Kowbel DJ, Lee J, et al. The regulatory and transcriptional landscape associated with 
carbon utilization in a filamentous fungus. Proc Natl Acad Sci U S A. 2020;117(11):6003-13.

21. Rassinger A, Gacek-Matthews A, Strauss J, Mach RL, Mach-Aigner AR. Truncation of the transcriptional repressor protein Cre1 in Trichoderma reesei Rut-C30 turns it into an activator. Fungal Biol Biotechnol. 2018;5:15.

22. Brown NA, Ries LNA, Goldman GH. How nutritional status signalling coordinates metabolism and lignocellulolytic enzyme secretion. Fungal Genet Biol. 2014;72:48-63.

23. Baker SE. Protein hyperproduction in fungi by design. Appl Microbiol Biotechnol. 2018;102(20):8621-8.

24. Tanaka M, Gomi K. Induction and repression of hydrolase genes in Aspergillus oryzae. Front Microbiol. 2021;12:677603.

25. Zhang T, Liu H, Lv B, Li C. Regulating strategies for producing Carbohydrate Active Enzymes by filamentous fungal cell factories. Front Bioeng Biotechnol. 2020;8:691.

26. Saloheimo M, Paloheimo M, Hakola S, Pere J, Swanson B, Nyyssönen E, et al. Swollenin, a Trichoderma reesei protein with sequence similarity to the plant expansins, exhibits disruption activity on cellulosic materials. Eur J Biochem. 2002;269(17):4202-11.

27. Kuhad RC, Deswal D, Sharma S, Bhattacharya A, Jain KK, Kaur A, et al. Revisiting cellulase production and redefining current strategies based on major challenges. Renew Sust Energ Rev. 2016;55:249-72.

28. Mello-de-Sousa TM, Rassinger A, Derntl C, Pocas-Fonseca MJ, Mach RL, Mach-Aigner AR. The relation between promoter chromatin status, Xyr1 and cellulase expression in Trichoderma reesei. Curr Genomics. 2016;17(2):145-52.

29. Häkkinen M, Valkonen MJ, Westerholm-Parvinen A, Aro N, Arvas M, Vitikainen $M$, et al. Screening of candidate regulators for cellulase and hemicellulase production in Trichoderma reesei and identification of a factor essential for cellulase production. Biotechnol Biofuels. 2014;7(1):14.

30. Coradetti ST, Craig JP, Xiong Y, Shock T, Tian CG, Glass NL. Conserved and essential transcription factors for cellulase gene expression in ascomycete fungi. Proc Natl Acad Sci U S A. 2012;109(19):7397-402.

31. Ivanova C, Ramoni J, Aouam T, Frischmann A, Seiboth B, Baker SE, et al. Genome sequencing and transcriptome analysis of Trichoderma reesei QM9978 strain reveals a distal chromosome translocation to be responsible for loss of vib1 expression and loss of cellulase induction. Biotechnol Biofuels. 2017:10:209.

32. Zhang F, Zhao X, Bai F. Improvement of cellulase production in Trichoderma reesei Rut-C30 by overexpression of a novel regulatory gene Trvib1. Bioresour Technol. 2018;247:676-83.

33. Zhang WX, Kou YB, Xu JT, Cao YL, Zhao GL, Shao J, et al. Two major facilitator superfamily sugar transporters from Trichoderma reesei and their roles in induction of cellulase biosynthesis. J Biol Chem. 2013;288(46):32861-72.

34. Novy V, Nielsen F, Seiboth B, Nidetzky B. The influence of feedstock characteristics on enzyme production in Trichoderma reesei: a review on productivity, gene regulation and secretion profiles. Biotechnol Biofuels. 2019;12(1):16

35. Schmoll M, Kubieek CP. ooc1, a unique gene expressed only during growth of Hypocrea jecorina (anamorph: Trichoderma reesei) on cellulose. Curr Genet. 2005;48(2):126-33.

36. Guangtao Z, Hartl L, Schuster A, Polak S, Schmoll M, Wang TH, et al. Gene targeting in a nonhomologous end joining deficient Hypocrea jecorina. J Biotechnol. 2009;139(2):146-51.

37. Liu GY, Sabatini DM. mTOR at the nexus of nutrition, growth, ageing and disease. Nat Rev Mol Cell Biol. 2020;21(4):183-203.

38. Liu YL, Duan XL, Zhao XD, Ding WL, Wang YW, Xiong Y. Diverse nitrogen signals activate convergent ROP2-TOR signaling in Arabidopsis. Dev Cell. 2021;56(9):1283

39. Fu L, Wang $\mathrm{P}$, Xiong $\mathrm{Y}$. Target of rapamycin signaling in plant stress responses. Plant Physiol. 2020;182(4):1613-23.

40. Jewell JL, Kim YC, Russell RC, Yu FX, Park HW, Plouffe SW, et al. Differential regulation of $\mathrm{mTORC1}$ by leucine and glutamine. Science. 2015;347(6218):194-8.

41. Pang AP, Wang H, Zhang F, Hu X, Wu FG, Zhou Z, et al. High-dose rapamycin exerts a temporary impact on $T$. reesei RUT-C30 through gene trFKBP12. Biotechnol Biofuels. 2021;14(1):77.
42. Blattner C, Jennebach S, Herzog F, Mayer A, Cheung AC, Witte G, et al. Molecular basis of Rrn3-regulated RNA polymerase I initiation and cell growth. Genes Dev. 2011;25(19):2093-105.

43. Domitrovic T, Fernandes CM, Boy-Marcotte E, Kurtenbach E. High hydrostatic pressure activates gene expression through Msn2/4 stress transcription factors which are involved in the acquired tolerance by mild pressure precondition in Saccharomyces cerevisiae. FEBS Lett. 2006;580(26):6033-8.

44. Conrad M, Schothorst J, Kankipati HN, Van Zeebroeck G, Rubio-Texeira M, Thevelein JM. Nutrient sensing and signaling in the yeast Saccharomyces cerevisiae. FEMS Microbiol Rev. 2014;38(2):254-99.

45. Griffith $A B$, Garrett RH. Xanthine dehydrogenase expression in Neurospora crassa does not require a functional nit-2 regulatory gene. Biochem Genet. 1988;26(1-2):37-52.

46. Aro N, Pakula T, Penttilä M. Transcriptional regulation of plant cell wall degradation by filamentous fungi. FEMS Microbiol Rev. 2005;29(4):719-39.

47. Portnoy T, Margeot A, Linke R, Atanasova L, Fekete E, Sandor E, et al. The CRE1 carbon catabolite repressor of the fungus Trichoderma reesei: a master regulator of carbon assimilation. BMC Genomics. 2011;12:12.

48. Ries LNA, Beattie SR, Espeso EA, Cramer RA, Goldman GH. Diverse regulation of the CreA carbon catabolite repressor in Aspergillus nidulans. Genetics. 2016;203(1):335-52.

49. Xiong Y, Sun JP, Glass NL. VIB1, a link between glucose signaling and carbon catabolite repression, is essential for plant cell wall degradation by Neurospora crassa. PLoS Genet. 2014;10(8):15.

50. Dementhon K, lyer G, Glass NL. VIB-1 is required for expression of genes necessary for programmed cell death in Neurospora crassa. Eukaryot Cell. 2006;5(12):2161-73

51. Heiden MGV, Cantley LC, Thompson CB. Understanding the Warburg Effect: the metabolic requirements of cell proliferation. Science. 2009;324(5930):1029-33.

52. Häkkinen M, Sivasiddarthan D, Aro N, Saloheimo M, Pakula TM. The effects of extracellular $\mathrm{pH}$ and of the transcriptional regulator $\mathrm{PACl}$ on the transcriptome of Trichoderma reesei. Microb Cell Fact. 2015;14:63.

53. Tisch D, Kubicek CP, Schmoll M. The phosducin-like protein PhLP1 impacts regulation of glycoside hydrolases and light response in Trichoderma reesei. BMC Genomics. 2011;12:21.

54. Hinterdobler W, Schuster A, Tisch D, Ozkan E, Bazafkan H, Schinnerl J, et al The role of PKAC1 in gene regulation and trichodimerol production in Trichoderma reesei. Fungal Biol Biotechnol. 2019;6:12.

55. Montero-Barrientos M, Hermosa R, Cardoza RE, Gutierrez S, Monte E. Functional analysis of the Trichoderma harzianum nox 1 gene, encoding an NADPH oxidase, relates production of reactive oxygen species to specific biocontrol activity against Pythium ultimum. Appl Environ Microbiol. 2011;77(9):3009-16.

56. Fingar DC, Blenis J. Target of rapamycin (TOR): an integrator of nutrient and growth factor signals and coordinator of cell growth and cell cycle progression. Oncogene. 2004;23(18):3151-71.

57. Wu C, Chen Y, Huang X, Sun S, Luo J, Lu Z, et al. An efficient shortened genetic transformation strategy for filamentous fungus Trichoderma reesei. J Gen Appl Microbiol. 2020;65(6):301-7.

58. Minty JJ, Singer ME, Scholz SA, Bae C-H, Ahn J-H, Foster CE, et al. Design and characterization of synthetic fungal-bacterial consortia for direct production of isobutanol from cellulosic biomass. Proc Natl Acad Sci U S A. 2013;110(36):14592-7.

59. Li C, Lin F, Li Y, Wei W, Wang H, Qin L, et al. A $\beta$-glucosidase hyperproduction Trichoderma reesei mutant reveals a potential role of cel3D in cellulase production. Microb Cell Fact. 2016;15(1):151.

60. Li C, Lin F, Sun W, Yuan S, Zhou Z, Wu FG, et al. Constitutive hyperproduction of sorbicillinoids in Trichoderma reesei ZC121. Biotechnol Biofuels. 2018;11:291.

61. Li C, Pang AP, Yang H, Lv R, Zhou Z, Wu FG, et al. Tracking localization and secretion of cellulase spatiotemporally and directly in living Trichoderma reesei. Biotechnol Biofuels. 2019;12:200.

62. Li C, Lin F, Zhou L, Qin L, Li B, Zhou Z, et al. Cellulase hyper-production by Trichoderma reesei mutant SEU-7 on lactose. Biotechnol Biofuels. 2017;10:228. 
63. Bischof R, Fourtis L, Limbeck A, Gamauf C, Seiboth B, Kubicek CP. Comparative analysis of the Trichoderma reesei transcriptome during growth on the cellulase inducing substrates wheat straw and lactose. Biotechnol Biofuels. 2013;6(1):127.

64. Zhang J, Zhang G, Wang W, Wang W, Wei D. Enhanced cellulase production in Trichoderma reesei RUT C30 via constitution of minimal transcriptional activators. Microb Cell Fact. 2018;17(1):75.

65. Pang A-P, Wang H, Luo Y, Yang Z, Liu Z, Wang Z, et al. Dissecting cellular function and distribution of beta-glucosidases in Trichoderma reesei. mBio. 2021;12(3):e03671-20.

66. Derntl C, Mach RL, Mach-Aigner AR. Fusion transcription factors for strong, constitutive expression of cellulases and xylanases in Trichoderma reesei. Biotechnol Biofuels. 2019;12(1):1-18.
67. Zhong YH, Wang XL, Wang TH, Jiang Q. Agrobacterium-mediated transformation (AMT) of Trichoderma reesei as an efficient tool for random insertional mutagenesis. Appl Microbiol Biotechnol. 2007;73(6):1348-54.

\section{Publisher's Note}

Springer Nature remains neutral with regard to jurisdictional claims in published maps and institutional affiliations.
Ready to submit your research? Choose BMC and benefit from:

- fast, convenient online submission

- thorough peer review by experienced researchers in your field

- rapid publication on acceptance

- support for research data, including large and complex data types

- gold Open Access which fosters wider collaboration and increased citations

- maximum visibility for your research: over $100 \mathrm{M}$ website views per year

At BMC, research is always in progress.

Learn more biomedcentral.com/submissions 